\title{
SOCIAL AND ERGONOMIC EVALUATION OF MOTORCYCLE PROTECTIVE ISOLATION SHIELD FOR REDUCING COMMUNITY SPREAD OF COVID-19
}

\author{
OLUKAYODE O. OYESIKU ${ }^{1}$, OLASUNKANMI O. AKINYEMI ${ }^{2}$, BASHIR O. \\ ODUFUWA ${ }^{3}$, BABATUNDE O. ADETIFA ${ }^{* 4}$ \\ ${ }^{1}$ Department of Geography, Olabisi Onabanjo University, Ago-Iwoye, Nigeria \\ ${ }^{2}$ Department of Mechanical Engineering, Olabisi Onabanjo University, Ago-Iwoye, Nigeria \\ ${ }^{3}$ Department of Urban and Regional Planning, Olabisi Onabanjo University, Ago-Iwoye, \\ Nigeria \\ ${ }^{4}$ Department of Agricultural Engineering, Olabisi Onabanjo University, Ago-Iwoye, \\ Nigeria
}

\begin{abstract}
Coronavirus (COVID-19) pandemic have rapidly evolved into a situation with profound effects on lifestyle and travel worldwide, ranging from a dramatic decrease in the patronage of formal public transport modes to an unprecedented increase in the usage of informal public transport modes. It is the main goal of this study to adapt a Motorcycle Protective Isolation Shield (MPIS) on a motorcycle for the reduction of community spread of COVID-19. MPIS was designed according to the anthropometry data obtained from motorcycle riders and passengers; and was fabricated using locally available materials. Anthropometry data used for the MPIS frame were sitting height (SH) and popliteal height (PH) of both motorcycle riders and passengers while seat depth (SD) of motorcycle riders and buttock knee length (BKL) of motorcycle passengers were used to locate the position of the MPIS mounted on the motorcycle. The 50\% of the anthropometry data used for the design of MPIS is $\mathrm{SH}=800.00 \mathrm{~mm}, \mathrm{PH}=500.00 \mathrm{~mm}, \mathrm{SD}=300.00 \mathrm{~mm}$ and $\mathrm{BKL}=550.00 \mathrm{~mm}$. The uncertainty modelling of motorcycle accident occurrence reveals the effect of higher speeds and the adapted MPIS during riding. The probability of occurrence of fatal crash, major crash and minor crash of motorcycle accident was $36.3 \%, 35.3 \%$ and $28.4 \%$, respectively. The MPIS showed satisfactory post-riding assessment in terms of riding stability; riding, steering, and sitting convenience; and riding comfort for both the riders and passengers. It will be a good protection for motorcycle riders against the risk of COVID-19 and other air-borne infections.
\end{abstract}

Keywords: COVID-19, motorcycle riders, Bayesian Belief Network, anthropometry, accident

\section{INTRODUCTION}

Transportation is an indispensable sector that enhances spatial interactions and facilitates the general development of the society. It also refers to both motorized and non-motorized modes of movement of people and/or goods

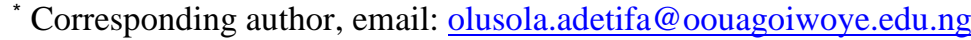

(C) 2021 Alma Mater Publishing House
} 
which have been found to be a great influence on society's safety and efficiency [1]. In Nigeria, airways, railways, road and waterways transportation serve the transportation needs of the populace. However, infrastructures available are inadequate, mismanaged, archaic and/or do not optimally fulfil the transportation demands of people, hence the need for the development of adapted technologies [2], especially for rural dwellers [3]. While discussing the importance of transport, Munby [4] reiterated that there is no escape from transport. This implies that virtually all activities of man in the society require transportation. Apart from the positive impacts of transportation towards the development of society, especially when operated optimally [5] it should be noted that transport and health are interrelated. For instance, the correlate between public transport and transmission of diseases is recently a subject of considerable practical importance and discourse [6]. A point of note is the outbreak of coronavirus disease that has drawn the attention of different stakeholders in the transport and health sectors in both advanced and less developed countries.

Furthermore, responses like lockdowns and restrictions on movement to mitigate the spread of COVID-19 [7, 8] by governments all over the world has suddenly impacted our way of life and that of the global transportation systems. The speed with which these impacts have hit the world is unprecedented, especially because the different modes of transport (airlines, railways, maritime and public road transport systems) have all experienced drastic fall of patronage. In Nigeria, Mogaji [8] stated that the lockdowns and restrictions on movement may not be effective, considering the high population density, poor transportation infrastructures and a large informal economy. Amongst the large informal economy is the use of motorcycle for lifting passengers. Emergent of the commercial motorcycle (also called taxi motorcycle) in most Nigeria cities has continuously been an issue of discourse among different stakeholders. Similarly, high demand for the service of commercial motorcycles is another worrisome matter. This means of travel have a great tendency of spreading the COVID-19 pandemic. This fact is attributable to the short distance between riders and passengers. This adds to the already identified health risks associated with the commercial motorcycle riding [9].

To evaluate the role of public transportation in the community spread of COVID-19, Noland [10] states that increasing mobility of the populace increases the community spread of COVID-19 as well as the reproductive rate of COVID-19. Zheng et al., [11] found a significant correlation between travels by train and spread of COVID-19 infections, but no correlation between travels by car and flight and spread of COVID-19 infections. Shen et al., [6] also found out that individual who rode a bus to a worship event in China with COVID-19 patient had a higher risk of COVID-19 infection than individuals who rode another bus to the same event without a COVID-19 patient. Zhen et al., [12] suggested that public awareness/enlightenment, staying at home when sick and minimizing public transport use as mitigation strategies for reduced risk of community spread of COVID-19 amongst public transport commuters.

In Nigeria, however, the government mandated public transport services to run at $50 \%$ capacity, but commercial motorcycles operators do not comply with this directive. Medical masks and face shields have been used by the populace but motorcycle taxi riders have an increased risk of acquiring coronavirus given the close contact of the riders with their passengers and airborne mode of spreading COVID-19. It is against this foregoing that this study adapts a Motorcycle Protective Isolation Shield (MPIS) towards mitigating community spread of the global pandemic, generally refers to as COVID-19.

There have been some interventions reported for taxi motorcycle riders against COVID-19. Purnomo and Ardiansyah [13], reported a shield backpack for taxi motorcyclists in Jakarta, while Athumani [14] reported the use of MPIS in Uganda for taxi motorcycles, developed by Dickson Ngirani. The report of the social, ergonomic and safety evaluation of these shields has not been reported. This study exposes not only the development process of the MPIS, but also the social evaluation of a motorcycle with MPIS, and an uncertainty evaluation of different accident scenarios of a motorcycle with MPIS.

\section{MATERIALS AND METHOD}

\subsection{Collection of Anthropometry Parameters for the design of MPIS}

The principle of application of anthropometry was used to obtain data for the design of the MPIS frame. This involved measuring body dimensions of commercial motorcycle riders and passengers necessary for the design of MPIS frame. Subsequently, the anthropometry data of 150 participants were successfully measured. This included 91 motorcycle riders $(60.7 \%)$ and 59 passengers (39.3\%). These subjects were randomly selected. The tool used for data collection was $150 \mathrm{~cm}$ ranged centimeter calibrated tape rule made of latex material. Figure 1 shows the 
anthropometry parameters measured and this include sitting height, popliteal height, seat depth (buttock-popliteal length) and buttock knee length. The data collected on the anthropometry measurements, from 150 participants, were analyzed using SPSS software to obtain percentile distribution measurements used for the fabrication of MPIS.

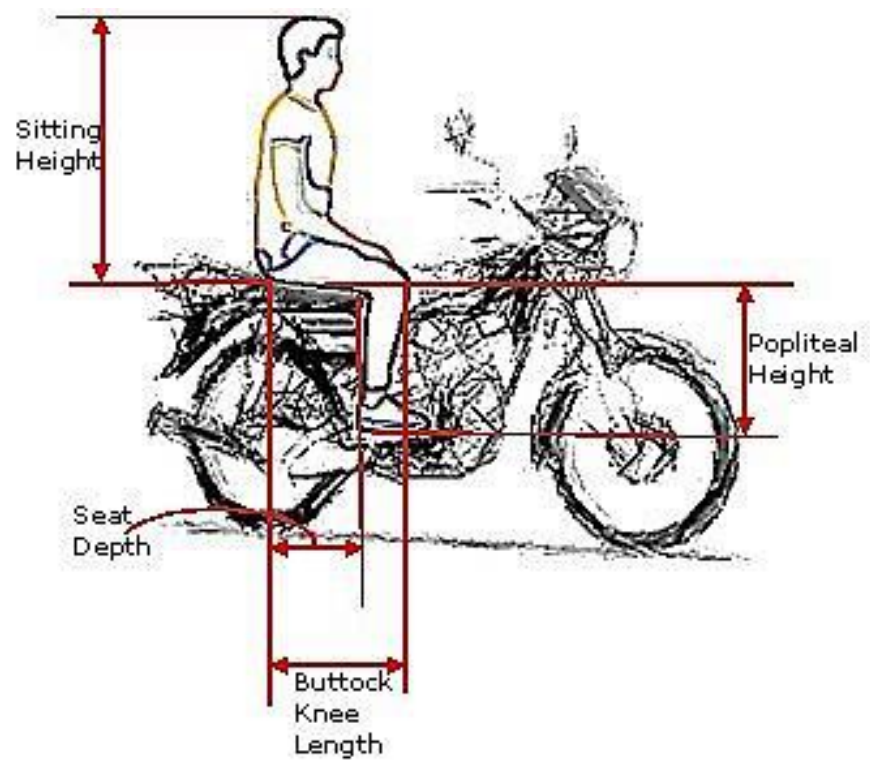

Fig. 1. Anthropometric measurements taken.

\subsection{Development of the MPIS}

The materials selected for the fabrication of the MPIS were a hollow steel pipe, transparent polymeric material, foam material and upholstery leather. The hollow steel pipe (squared) was selected based on its formability and ductility properties while the transparent polymeric material was selected due to its low hazardous condition in the event of mishaps while the steel frame was upholstered to prevent hazardous conditions between the rider, passenger and the MPIS frame. It should be noted that the transparent polymeric material used as the isolation shield was carefully fixed on the MPIS frame using rivets.

\subsection{Performance Evaluation of MPIS Adapted Motorcycle}

To evaluate the rider's and passenger's behaviour on the use and acceptability of MPIS, this study relied on the social evaluation questionnaires developed for both the riders and passengers. The questionnaires addressed demographic characteristics of respondents, post riding assessment, comfort and discomfort experienced during riding. Quantitative responses were obtained using the Likert Scale calculated on a scale of 1 (extremely poor) to 10 (excellent) for post riding assessment of the motorcycle with MPIS.

\subsection{Accident Evaluation of MPIS}

The unlikeliness of an event to occur (or low probability of occurrence) does not imply the event will not happen. To this end, Bayesian Belief Network modelling was used to evaluate the uncertainty surrounding the effect of motorcycle accident hazards on the use of the motorcycle with MPIS. This methodology involves determining prior probability of parent and child nodes, developing influence diagram and conditional probability table (CPT) for the child node and carrying out causal and diagnostic inferences.

The Prior Probabilities of the motorcycle accident hazards were obtained from expert judgments, while CPT was also developed for the child node scenarios using expert judgments. It should be noted that the child node scenario is the occurrence of the consequences (namely fatal crash, major crash and minor crash) of motorcycle accident of motorcycle with MPIS. Hazards leading to motorcycle accident have been categorized into eight groups and these hazards acted as the parent nodes in the Bayesian influence diagrams acting on the child node. The influence diagram was developed using Bayesian Network Software called Netica.

Furthermore, Bayesian causal inference was carried out to evaluate the probability of occurrence of consequences of motorcycle accident while Bayesian diagnostic inference was carried out to evaluate the critical motorcycle 
accident hazards. The diagnostic inference determines the posterior probability of motorcycle accident hazards and consequently the critical motorcycle accident hazards were evaluated.

\section{RESULTS AND DISCUSSION}

\subsection{Anthropometric Data for Motorcycle Riders and Passengers}

The assessment of anthropometric data of the 150 participants was aimed at getting the required data for the design of the MPIS. Table 1 shows the means, standard deviations and 5th -90 th percentile of anthropometric data of body dimensions of motorcycle riders and passengers used for the dimensions of the components of the MPIS. This result shows that the mean sitting height, popliteal height, seat depth (buttock-popliteal length) and buttock knee-length were $800,500,300$ and $550 \mathrm{~mm}$, respectively. Although anthropometric data of Nigeria's motorcyclists are scarce in the literature, this result compares well with the few reported data. Rajhans and Amrutkar [15] reported that the mean popliteal height, buttock-popliteal length and buttock knee length of motorcycle riders in India are 420, 453 and $832 \mathrm{~mm}$, respectively. Although only the popliteal height falls within the range observed in this study, the buttock knee-length reported in this study falls within the range of that of motorcycle riders in the UK between the ages of 19-65 years $(595 \mathrm{~mm})$ reported by Stedmon et al. [16]. The $90^{\text {th }}$ percentile of the seating depth of this study is close to the minimum value of the seating depth of Malaysian riders between the ages of 18-24 years $(358 \mathrm{~mm})$ reported by Karuppiah et al. [17]. These discrepancies in the anthropometric data of the different populations justify the need to carry out specific measurements for the population under study.

Table 1. Measured anthropometric data of motorcycle riders and passengers $(\mathrm{N}=150)$.

\begin{tabular}{|c|c|c|c|c|}
\hline & PH (mm) & BKL $(\mathbf{m m})$ & SD $(\mathbf{m m})$ & SH (mm) \\
\hline Mean & 500.00 & 550.00 & 300.00 & 800.00 \\
\hline SD & 50.00 & 90.75 & 50.08 & 110.25 \\
\hline $5^{\mathrm{TH}}$ & 360.30 & 390.85 & 210.00 & 690.25 \\
\hline $25^{\mathrm{TH}}$ & 480.00 & 500.00 & 270.00 & 770.35 \\
\hline $50^{\mathrm{TH}}$ & 500.00 & 550.00 & 300.00 & 800.00 \\
\hline $75^{\mathrm{TH}}$ & 520.75 & 580.50 & 320.00 & 820.00 \\
\hline $90^{\mathrm{TH}}$ & 550.00 & 610.00 & 350.00 & 850.00 \\
\hline
\end{tabular}

\subsection{Components of MPIS}

Figure 2 shows the four major components of the MPIS. It comprises the MPIS frame, the transparent shield, frame cover and the MPIS leg support. The transparent shield was riveted into and held in place by the MPIS frame. For the safety of the user, the MPIS was covered by the MPIS frame cover (made of foam and upholstery materials). The MPIS assembly was attached to a motorcycle using the MPIS leg support.

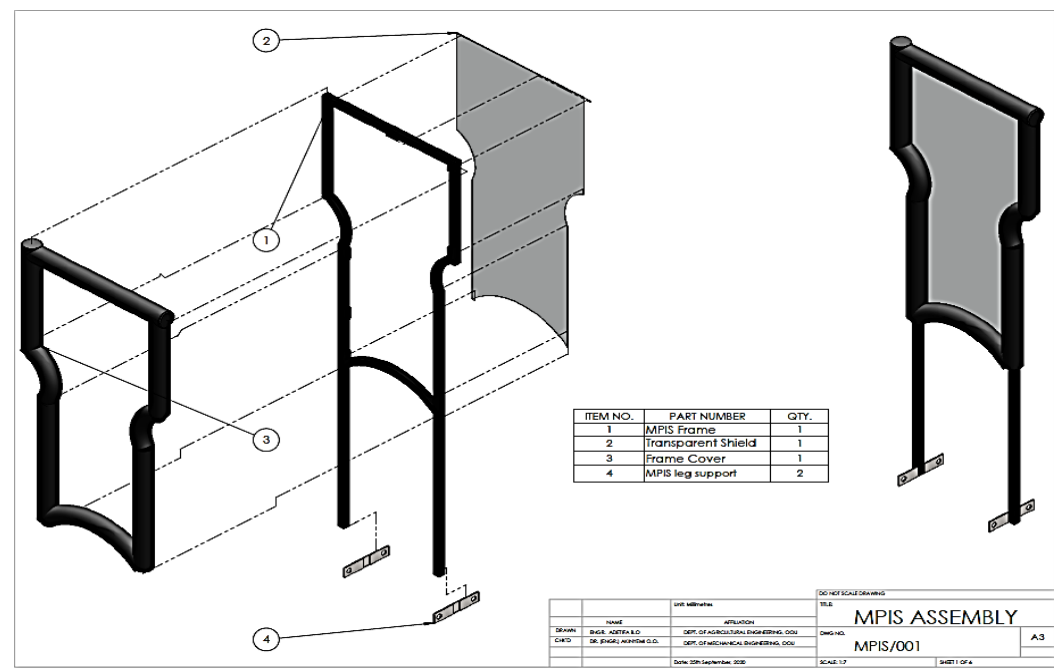

Fig. 2. Exploded view of Motorcycle Protective Isolation Shield (MPIS) 
Figures 3, 4, 5 and 6 show the engineering drawings of the MPIS frame, MPIS transparent shield, MPIS framecover and MPIS leg support, respectively, while Figure 7 shows the different views of the MPIS assembly.

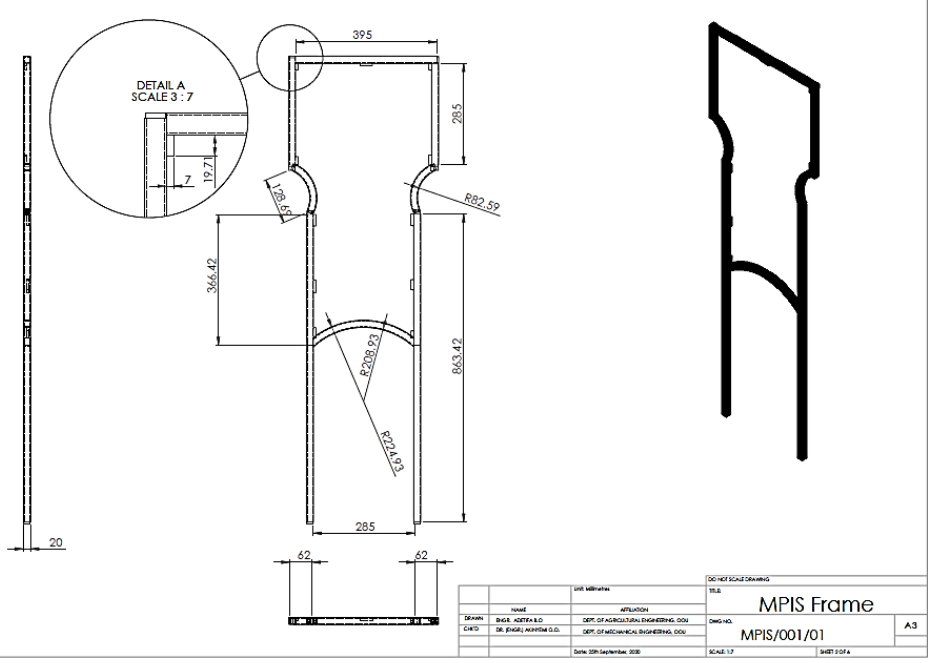

Fig. 3. Dimensions of MPIS frame.

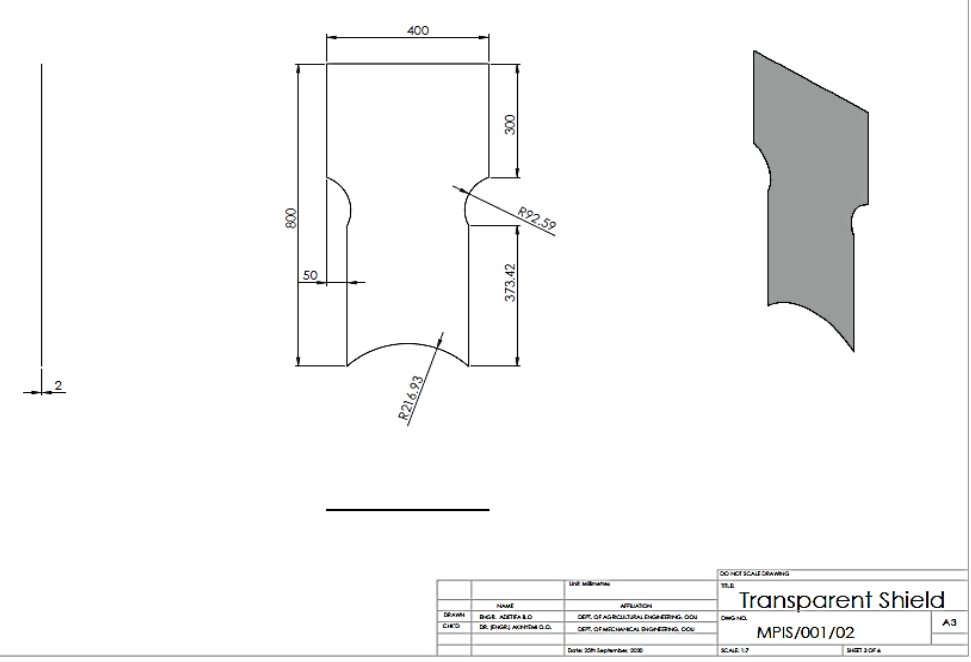

Fig. 4. Schematic drawing of MPIS transparent shield.

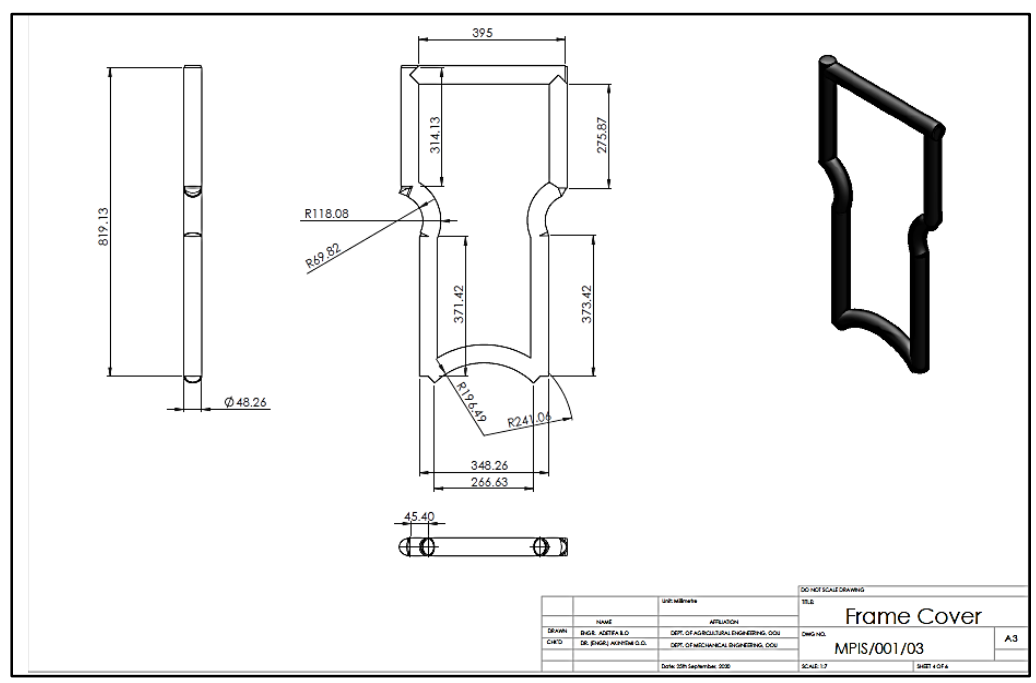

Fig. 5. Schematic drawing of MPIS frame cover. 


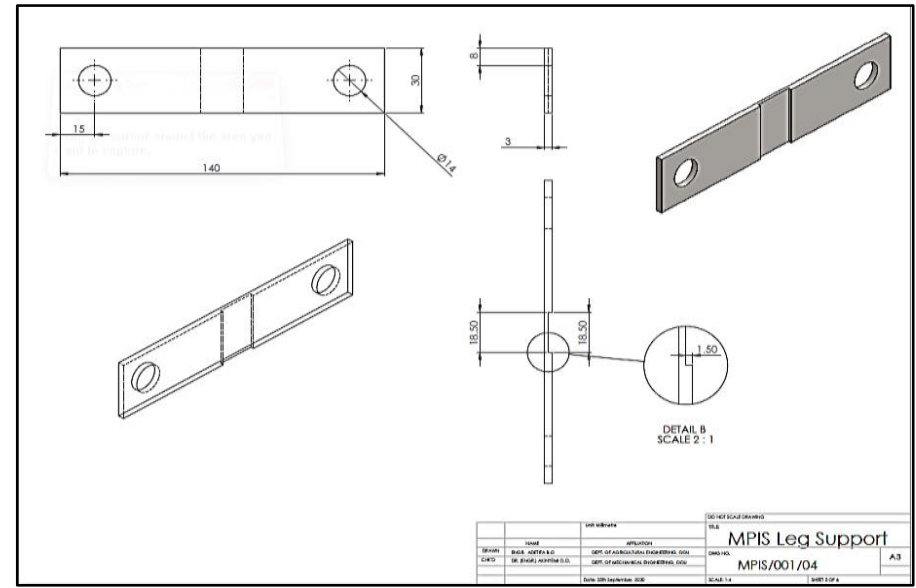

Fig. 6. Schematic drawing of MPIS leg support.

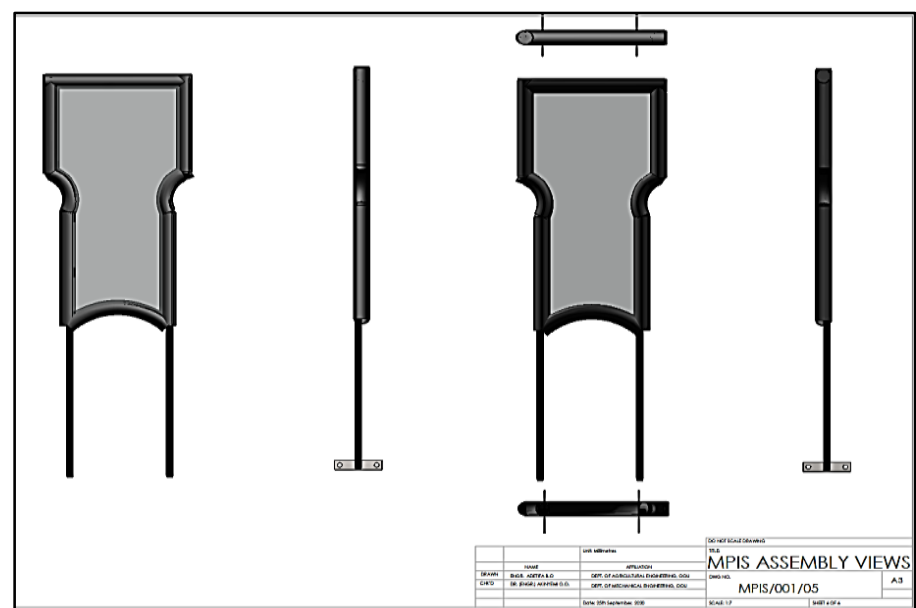

Fig. 7. MPIS Assembly.

\subsection{Fabrication of MPIS}

The $50^{\text {th }}$ percentile values of the anthropometry data were used for the dimensions of the MPIS because it is the average dimensions of the sample population. The values of sitting height of motorcycle riders were used for the height of the MPIS; the popliteal height of passengers was used for the MPIS stand while the seat depth of motorcycle riders and buttock knee length of passengers were used to locate the position of the MPIS mounted on the motorcycle. Table 2 shows the dimensions of components of the MPIS while Figures 8, 9 and 10 show the fabricated MPIS; a motorcycle with MPIS, rider, and passenger; and a motorcycle with MPIS. As a safety precaution, the MPIS was upholstered. Thus, apart from preventing contact between riders and passengers (enhanced social distancing); it will guard against injury/collision in the case of accident occurrence.

Table 2. Components of MPIS.

\begin{tabular}{|c|c|c|c|}
\hline S/N & Components/Sections & $50^{\text {th }}$ percentile & Dimensions of MPIS \\
\hline 1 & MPIS frame (hollow steel pipe (squared) $1.5 \mathrm{~mm})$ & Sitting height of riders & $\begin{array}{c}\text { Height of MPIS } \\
(800 \times 400 \mathrm{~mm})\end{array}$ \\
\hline 2 & MPIS stand (hollow steel pipe (squared) $1.5 \mathrm{~mm})$ & $\begin{array}{c}\text { Popliteal height of a } \\
\text { passenger }\end{array}$ & $\begin{array}{c}\text { MPIS stand } \\
(500 \mathrm{~mm})\end{array}$ \\
\hline
\end{tabular}




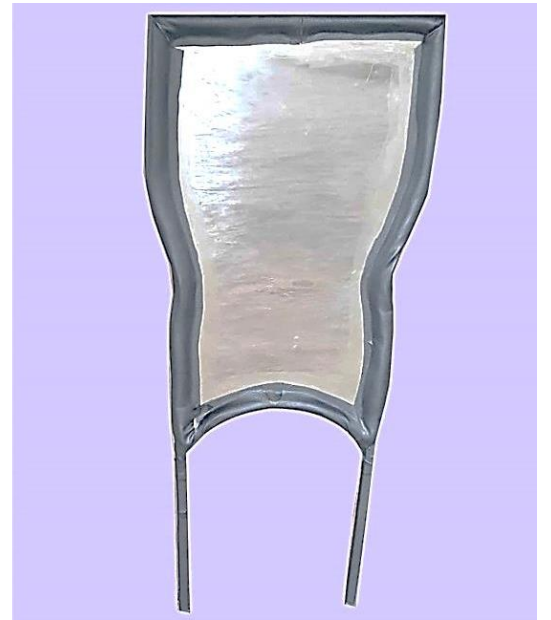

Fig. 8. Fabricated motorcycle protective isolation shield.

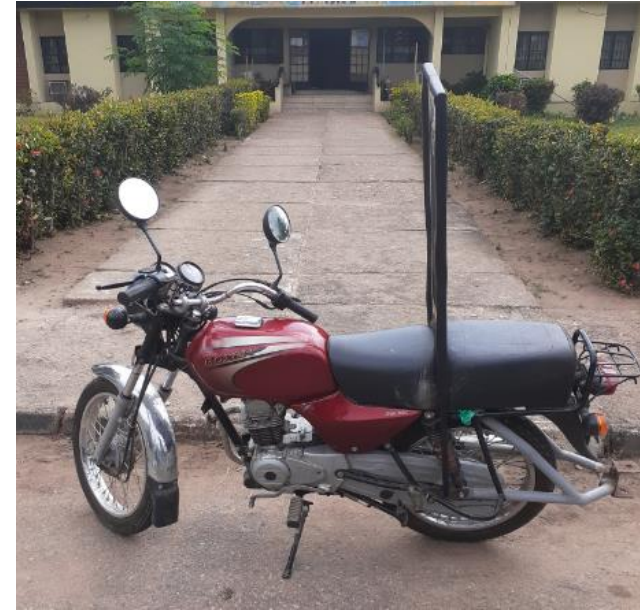

Fig. 9. A motorcycle with MPIS.

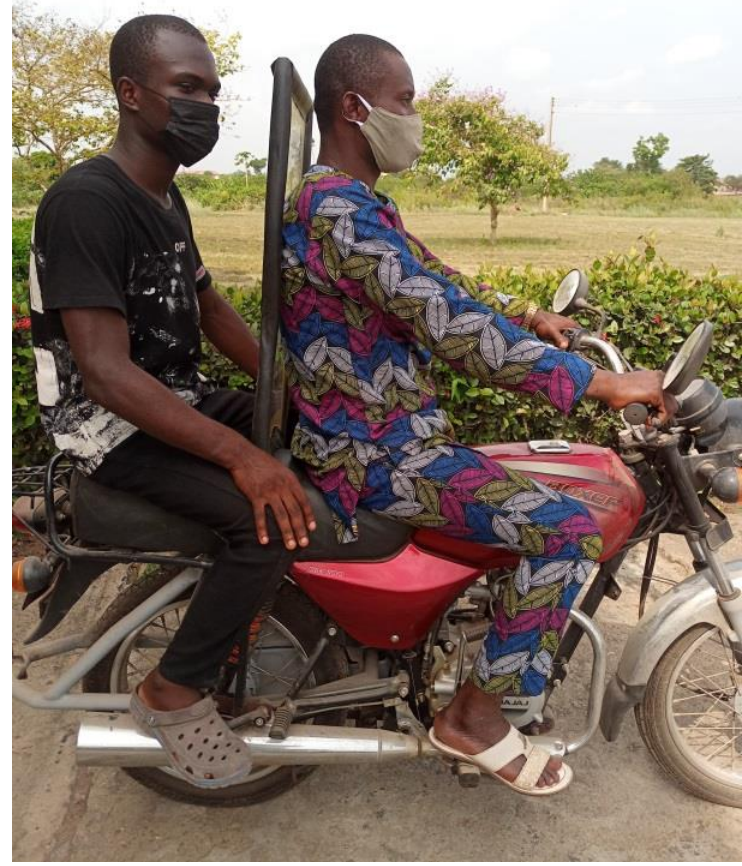

Fig. 10. Rider and passenger on motorcycle with MPIS.

\subsection{Social Evaluation of MPIS}

Table 3 shows the demographic information of motorcycle with MPIS for riders and passengers. Motorcycle riders were majorly males $(100 \%)$ and aged between 25 and 34 years $(96 \%)$. Meanwhile, most users (passengers) of commercial motorcycles are between 20 and 54 years. Similar to this, Oluwadiya et al. [18] reported the mean ages of motorcycle riders and passengers around selected states in Nigeria (Kwara, Kogi, parts of Niger, Osun, Oyo, Ekiti and Ondo State) to be 35.5 and 31.4 years, respectively. It is pertinent to reiterate that passengers of commercial motorcycles are not limited to specific age brackets. This implies that personal ability to withstand mobility distress associated with motorcycle and other related motorcycle patronage factors are inevitable determinants of the use of commercial motorcycles.

Sequel to the determinants of patronage of commercial motorcycle, literacy level is an important factor. Thus, this study reveals that most riders/operators of commercial motorcycles possess primary (32\%) and secondary school education $(32 \%)$. It is however important to note that, about $36 \%$ of the operators lack formal education. The inference that could be drawn from these findings is that with or without formal education, motorcycles can be 
operated in the study area. Meanwhile, towards ensuring the safety of passengers and riders; the need for transport education, particularly for the operators was emphasized to be one of the criteria to be considered before authorization of commercial motorcycle operation. Passenger's education and patronage of commercial motorcycles were noted to be a vital determining factor for the use of commercial motorcycles [19]. Based on this notion, this study reveals that most passengers $(52 \%)$ have a secondary school education, while $8 \%$ has no formal education. It is interesting to note that a notable proportion (40\%) of motorcycle passengers has tertiary education. This implies that while most of the passengers have sufficient education to understand the need and acceptability of the MPIS, there is need to sensitize the riders on the adoption of MPIS based on their relatively low level of education.

Also, it was observed that $48 \%$ of the motorcycle riders are artisans, but operates commercial motorcycles on a part-time basis (this is common in the study area), also confirming the report of Oyesiku and Odufuwa [20] and Oyesiku [21]; while $52 \%$ are unemployed and are engaged as full-time riders. The occupation of passengers ranges from Civil Servant $(8 \%)$ to trader $(60 \%)$ with a student population of $20 \%$. It is interesting to note that about 88 $\%$ of the operators have over 20 years of riding experience. This shows that a good proportion has riding experience which is a significant pointer towards safety and accident-free riding. Meanwhile, the riding experience of motorcycle passengers ranges from $16-20$ years $(48 \%)$ to $6-10$ years $(52 \%)$ ). Also, the riding frequency (every day, $100 \%$ ) and the average riding distance per trip (above $1.2 \mathrm{~km}, 100 \%$ ) were covered by both motorcycle riders and passengers.

Post riding evaluations of motorcycle with MPIS by riders is shown in Tables 4 and 5 . About $58 \%$ of the riders have challenges while riding the motorcycle with MPIS. Indeed, $41 \%$ of the riders complained about sitting posture; $31 \%$ complained about the riding stability, while about $14 \%$ complained about steering and riding respectively. It is pertinent to note that each of these challenges affects the riding satisfaction of the riders. For instance, sitting posture and steering affects the ability of riders to maneuvered potholes and bends on the road. Similarly, concerning the anthropometry evaluation, some riders whose body measurements fell outside the $50^{\text {th }}$ percentile affirmed the gross body contact with the adapted MPIS.

As shown in Figure 11, the post riding evaluation performance reveals that cycle stability when riding straight at moderate speed has the highest rating; this was closely followed by cycle stability when riding straight at high speed. Meanwhile, cycle stability when riding along bends, steering convenience and sitting convenience have the lowest rating respectively.

Table 3. Demographic information of motorcycle with MPIS riders and passengers (Source: Authors' fieldwork).

\begin{tabular}{|c|c|c|c|}
\hline & & Passenger $(\mathrm{n}=50)$ & Rider $(n=50)$ \\
\hline \multirow{2}{*}{ Sex } & Female & $40.0 \%$ & $0.0 \%$ \\
\hline & Male & $60.0 \%$ & $100.0 \%$ \\
\hline \multirow{4}{*}{ Age group } & 20-24 years & $20.0 \%$ & $0.0 \%$ \\
\hline & 25-34 years & $16.0 \%$ & $96.0 \%$ \\
\hline & 35-44 years & $32.0 \%$ & $4.0 \%$ \\
\hline & $45-54$ years & $32.0 \%$ & $0.0 \%$ \\
\hline \multirow{4}{*}{ Education } & No Formal Education & $8.0 \%$ & $36.0 \%$ \\
\hline & Primary school & $0.0 \%$ & $32.0 \%$ \\
\hline & Secondary School & $52.0 \%$ & $32.0 \%$ \\
\hline & Tertiary Education & $40.0 \%$ & $0.0 \%$ \\
\hline \multirow{5}{*}{ Occupation } & Artisan/Professional & $12.0 \%$ & $48.0 \%$ \\
\hline & Civil Servant & $8.0 \%$ & $0.0 \%$ \\
\hline & Full-time rider & $0.0 \%$ & $52.0 \%$ \\
\hline & Student & $20.0 \%$ & $0.0 \%$ \\
\hline & Trader & $60.0 \%$ & $0.0 \%$ \\
\hline \multirow{3}{*}{ Riding experience } & $>20$ years & $0.0 \%$ & $88.0 \%$ \\
\hline & 16-20 years & $48.0 \%$ & $4.0 \%$ \\
\hline & $6-10$ years & $52.0 \%$ & $8.0 \%$ \\
\hline Riding frequency & Everyday & $100.0 \%$ & $100.0 \%$ \\
\hline Average riding distance per trip & More than $1.2 \mathrm{~km}$ & $100.0 \%$ & $100.0 \%$ \\
\hline \multirow{2}{*}{ Riding Licence } & No & $0.0 \%$ & $92.0 \%$ \\
\hline & Yes & $0.0 \%$ & $8.0 \%$ \\
\hline
\end{tabular}


Table 4. Riders Challenges with MPIS motorcycle.

\begin{tabular}{|c|c|c|}
\hline & Frequency & $\%$ \\
\hline Yes & 29 & 58 \\
\hline No & 21 & 42 \\
\hline Total & 50 & 100 \\
\hline
\end{tabular}

Table 5. Challenging Factors of MPIS motorcycle riders.

\begin{tabular}{|c|c|c|}
\hline Problem areas & Frequency & $\%$ \\
\hline Sitting & 12 & 41 \\
\hline Riding & 4 & 14 \\
\hline Steering & 4 & 14 \\
\hline Stability & 9 & 31 \\
\hline Total & 29 & 100 \\
\hline
\end{tabular}

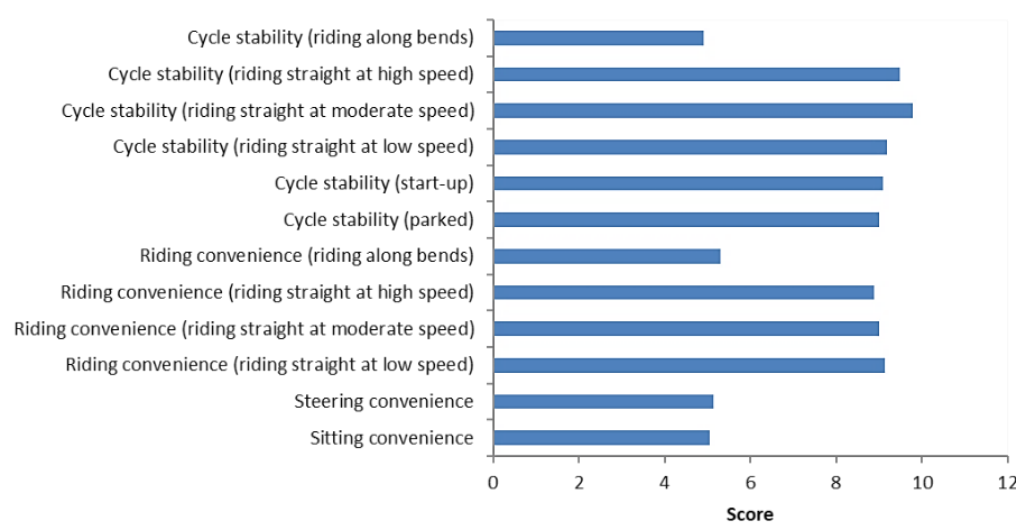

Fig. 11. Riders' rating of the motorcycle with MPIS.

Similarly, post riding evaluation of the motorcycle with MPIS by passengers is shown in Tables 6 and 7. About $52 \%$ of the passengers have challenges while riding the motorcycle with MPIS. $39 \%$ of the passengers complained about sitting posture; $35 \%$ complained about the riding stability, while about $26 \%$ complained about hand support used by the passengers during riding. As noted earlier, these challenges affect the riding satisfaction of passengers. For instance, sitting posture and hand support used by the passengers during riding affects the comfortability of passengers when loads are carried and whenever the clutch is applied abruptly by riders during riding. It was suggested that a backrest be fabricated to support the passengers during riding.

As shown in Figure 12, the post riding evaluation performance reveals that cycle stability when riding straight at high speed has the highest rating; this was closely followed by cycle stability at moderate speed. Meanwhile, sitting convenience and hand support has the lowest rating respectively.

Table 6. Passengers Challenges with MPIS motorcycle.

\begin{tabular}{|c|c|c|}
\hline & Frequency & $\%$ \\
\hline Yes & 26 & 52 \\
\hline No & 24 & 48 \\
\hline Total & 50 & 100 \\
\hline
\end{tabular}

Table 7. Challenging Factors of MPIS motorcycle passengers.

\begin{tabular}{|c|c|c|}
\hline Problem areas & Frequency & $\%$ \\
\hline Sitting & 10 & 39 \\
\hline Front view & 0 & 0 \\
\hline Side view & 0 & 0 \\
\hline Stability & 9 & 35 \\
\hline Face shield & 0 & 0 \\
\hline Hand support & 7 & 26 \\
\hline Total & 26 & 100 \\
\hline
\end{tabular}




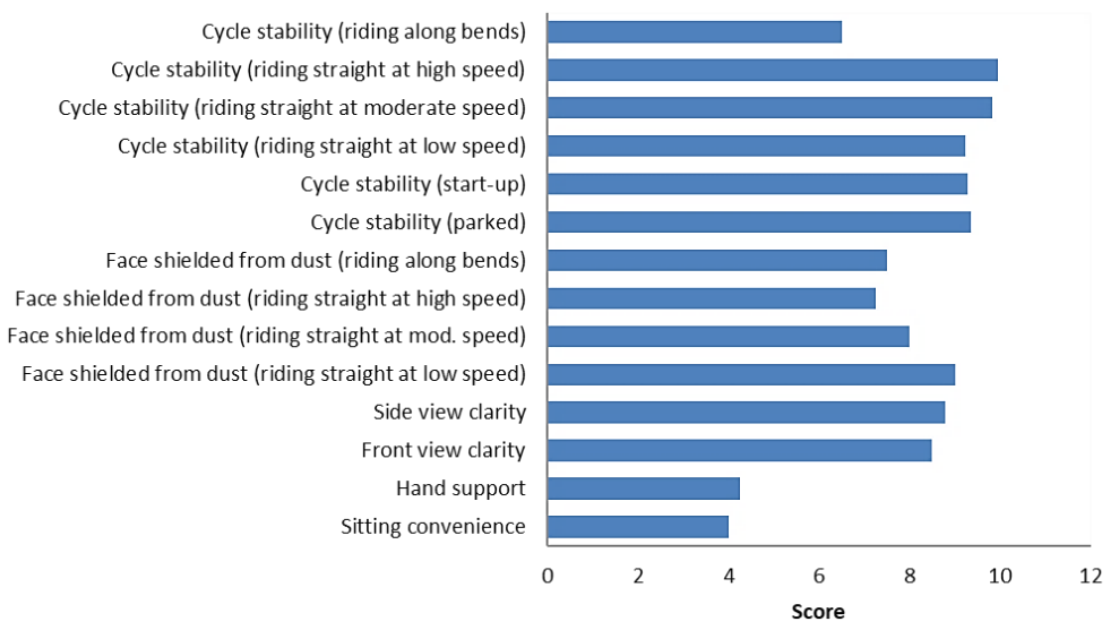

Fig. 12. Passengers' rating of the motorcycle with MPIS.

Furthermore, Table 8 showed that about $45 \%$ of riders experienced discomfort (in the form of body pains) in their legs; $34 \%$ in their waist/backrest and $21 \%$ in their hands during and after riding. This is evident in the challenges experienced by riders as aforesaid. In the same vein, Table 9 showed that about $35 \%$ of passengers experienced discomfort during and after riding in their waist/backrest, $27 \%$ in their hands and 19\% in their knees/thighs and legs respectively. Meanwhile, Tables 10 and 11 showed that $42 \%$ and $48 \%$ of riders and passengers found riding on the motorcycle with MPIS not stressful.

Table 8. Parts of the body riders experience discomfort and/or pain.

\begin{tabular}{|c|c|c|}
\hline Problem areas & Frequency & $\%$ \\
\hline Knees/Thighs & 0 & 0 \\
\hline Hand & 6 & 21 \\
\hline Waist/Backrest & 10 & 34 \\
\hline Legs & 13 & 45 \\
\hline Total & 29 & 100 \\
\hline
\end{tabular}

Table 9. Parts of the body passengers experience discomfort and/or pain.

\begin{tabular}{|c|c|c|}
\hline Problem areas & Frequency & $\%$ \\
\hline Knees/Thighs & 5 & 19 \\
\hline Hand & 7 & 27 \\
\hline Waist/Backrest & 9 & 35 \\
\hline Legs & 5 & 19 \\
\hline Total & 26 & 100 \\
\hline
\end{tabular}

Table 10. How do riders find riding the motorcycle with this shield?

\begin{tabular}{|c|c|c|}
\hline & Frequency & $\%$ \\
\hline Not stressful & 21 & 42 \\
\hline Mildly stressful & 29 & 58 \\
\hline Stressful & 0 & 0 \\
\hline Very stressful & 0 & 0 \\
\hline Total & 50 & 100 \\
\hline
\end{tabular}

Table 11. How do passengers find riding the motorcycle with this shield?

\begin{tabular}{|c|c|c|}
\hline & Frequency & $\%$ \\
\hline Not stressful & 24 & 48 \\
\hline Mildly stressful & 26 & 52 \\
\hline Stressful & 0 & 0 \\
\hline Very stressful & 0 & 0 \\
\hline Total & 50 & 100 \\
\hline
\end{tabular}


It should be noted that the motorcycle with MPIS is suitable for one passenger at a time as against the 2 or 3 passengers usually carried. Although, there is no empirical evidence to show the reduction of community spread of COVID-19 as a result of using the motorcycle with MPIS; it is believed that the reduced number of motorcycle passengers and the mounted MPIS represent an important component of the overall effort that will greatly reduce risk of community spread. Conversely, the reduced number of motorcycle passengers was frown at by commercial motorcycle riders due to the reduced financial viability. If government directives are strictly enforced; the implementation of this motorcycle with MPIS as a public transport policy will reduce or mitigate the community spread of COVID-19.

\subsection{Uncertainty Evaluation of MPIS}

The states and prior probability for the eight (8) motorcycle accident hazards were given in Table 12. The Bayesian causal inference was run using the Bayesian Network software, Netica. The probability of occurrence of fatal crash of motorcycle accident is $31.7 \%$, major crash of motorcycle accident is $34.5 \%$ and minor crash of motorcycle accident is $33.7 \%$ respectively as shown in Figure 13.

Table 12. States of parent nodes and their corresponding prior probabilities.

\begin{tabular}{|c|c|c|c|c|}
\hline $\mathrm{S} \mid \mathrm{N}$ & Variables & Symbols & States & Prior Probabilities (\%) \\
\hline 1 & Use of Helmet & Helmet & $\begin{array}{l}\text { Yes } \\
\text { Not }\end{array}$ & $\begin{array}{c}5.0 \\
95.0\end{array}$ \\
\hline 2 & Over Speeding & OverSpeeding & $\begin{array}{l}\text { Yes } \\
\text { No }\end{array}$ & $\begin{array}{l}65.0 \\
35.0\end{array}$ \\
\hline 3 & Musculoskeletal Disorder & MSD & $\begin{array}{c}\text { Rider } \\
\text { Passenger }\end{array}$ & $\begin{array}{l}35.0 \\
65.0\end{array}$ \\
\hline 4 & Road & Road & $\begin{array}{c}\text { Two-Lane Highway } \\
\text { Four-Lane Highway } \\
\text { EarthenRoad } \\
\text { BitumenRoad }\end{array}$ & $\begin{array}{l}30.0 \\
10.0 \\
30.0 \\
30.0\end{array}$ \\
\hline 5 & Time of the Day & TimeoftheDay & $\begin{array}{c}\text { Day } \\
\text { Night }\end{array}$ & $\begin{array}{l}50.0 \\
50.0\end{array}$ \\
\hline 6 & Collision Type & CollisionType & $\begin{array}{c}\text { MotorcycletoCar } \\
\text { MotorcycletoPedestrian } \\
\text { MotorcycletoHeavyTruck } \\
\text { MotorcycletoMotorcycle }\end{array}$ & $\begin{array}{l}15.0 \\
10.0 \\
35.0 \\
40.0\end{array}$ \\
\hline 7 & Loss of Control & LossOfControl & $\begin{array}{l}\text { Yes } \\
\text { No }\end{array}$ & $\begin{array}{l}40.0 \\
60.0\end{array}$ \\
\hline 8 & $\begin{array}{l}\text { Motorcycle Protection } \\
\text { Isolation Shield }\end{array}$ & MPIS & $\begin{array}{l}\text { Yes } \\
\text { No }\end{array}$ & $\begin{array}{l}50.0 \\
50.0\end{array}$ \\
\hline
\end{tabular}

Figures 14, 15 and 16 show the posterior probability of occurrence of fatal crash of motorcycle accident, the posterior probability of major crash of motorcycle accident and the posterior probability of minor crash of motorcycle accident respectively.

When the posterior probability obtained is compared with the prior probability, it is observed that there are changes in the values of the probability of occurrence of the parent nodes. Changes observed in the probability of occurrence of fatal crash of motorcycle accident are in the probability of occurrence of OverSpeeding = Yes (increased by $13.2 \%$ ) and LossOfControl = Yes (increased by $14.8 \%$ ) while marginal changes are observed in the probability of occurrence of Road $=$ TwoLaneHW (increased by $6.3 \%$ ), CollisionType = MotorcycletoHeavyTruck (increased by $5.1 \%$ ), MSD = Rider (increased by $4 \%$ ), Road = EarthenRoad (increased by $2.7 \%$ ), TimeoftheDay = Night (increased by 1.6\%) and MPIS = Yes (increased by $1.4 \%$ ). This implies that fatal crash of the motorcycle with MPIS is sensitive to loss of control, overspeeding, road type and collision type. In the same vein, changes were observed in the probability of occurrence of motorcycle accident hazards for major crash motorcycle accident and minor crash motorcycle accident respectively. 


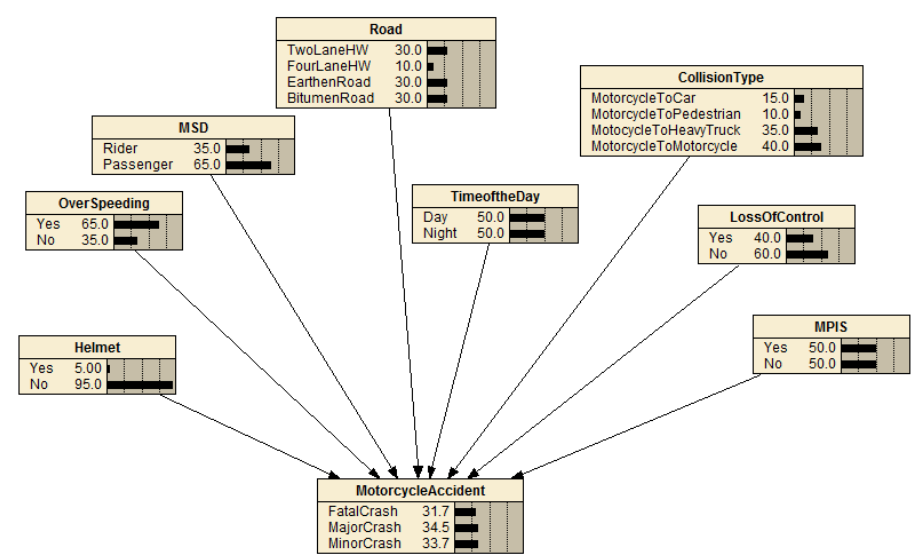

Fig. 13. Bayesian causal inference of occurrence of the consequence of motorcycle accident with MPIS.

Figure 17 shows the diagnostic inference of the specific effect of over speeding (higher speeds) and the adapted MPIS. The inference reveals notable change in the posterior probability of occurrence of MotorcycleAccident $=$ FatalCrash (increased by $14.5 \%$ ) and a marginal change in the posterior probability of occurrence of MotorcycleAccident = MajorCrash (increased by $2.3 \%$ ) while no positive change was observed in the posterior probability of occurrence of MotorcycleAccident $=$ MinorCrash (decreased by $15.7 \%$ ).

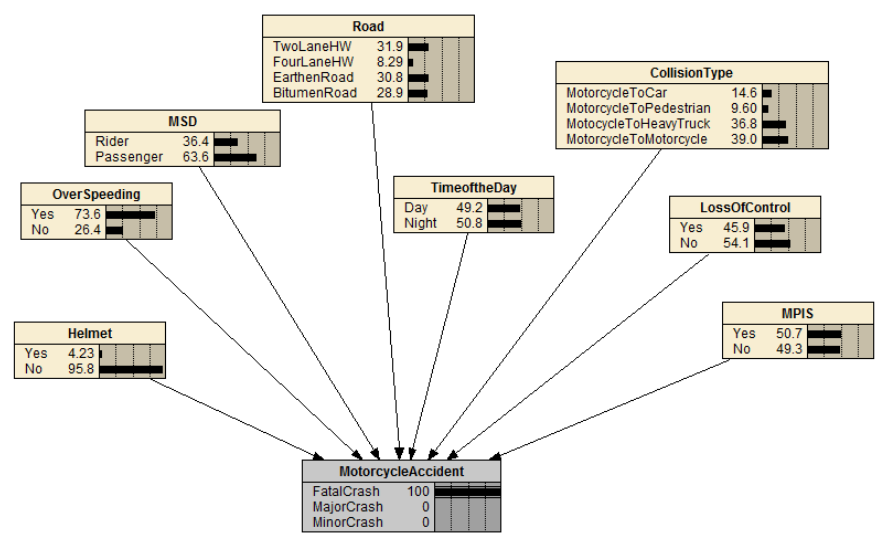

Fig. 14. Bayesian diagnostic inference of the occurrence of fatal crash motorcycle accident of motorcycle with MPIS.

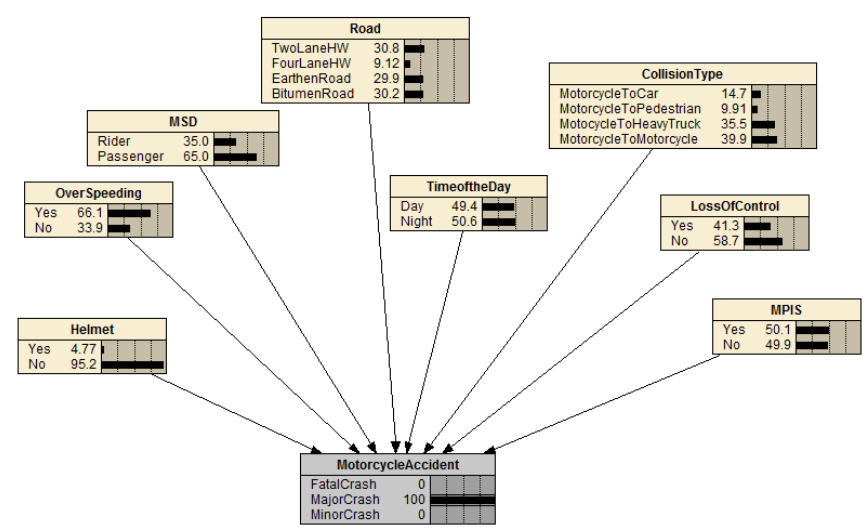

Fig. 15. Bayesian diagnostic inference of the occurrence of major crash motorcycle accident of motorcycle with MPIS 


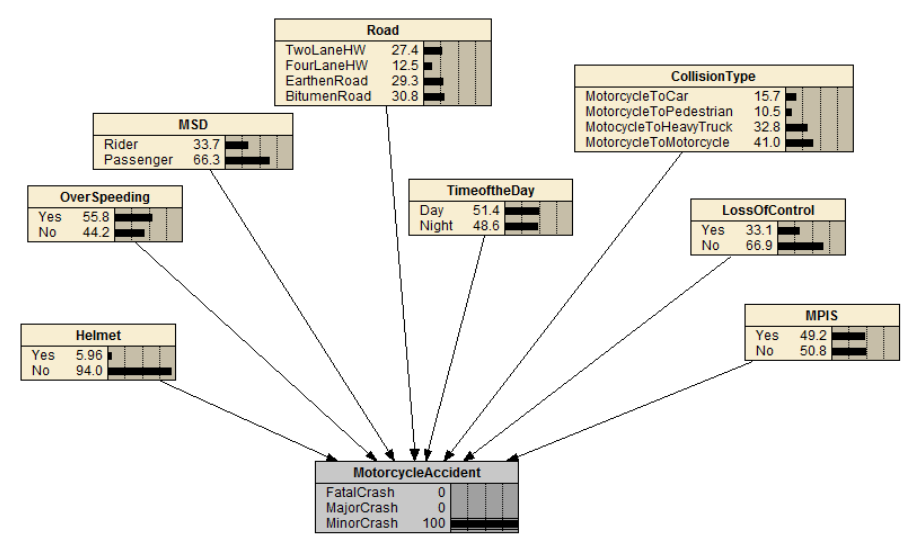

Fig. 16. Bayesian diagnostic inference of the occurrence of minor crash motorcycle accident of motorcycle with MPIS

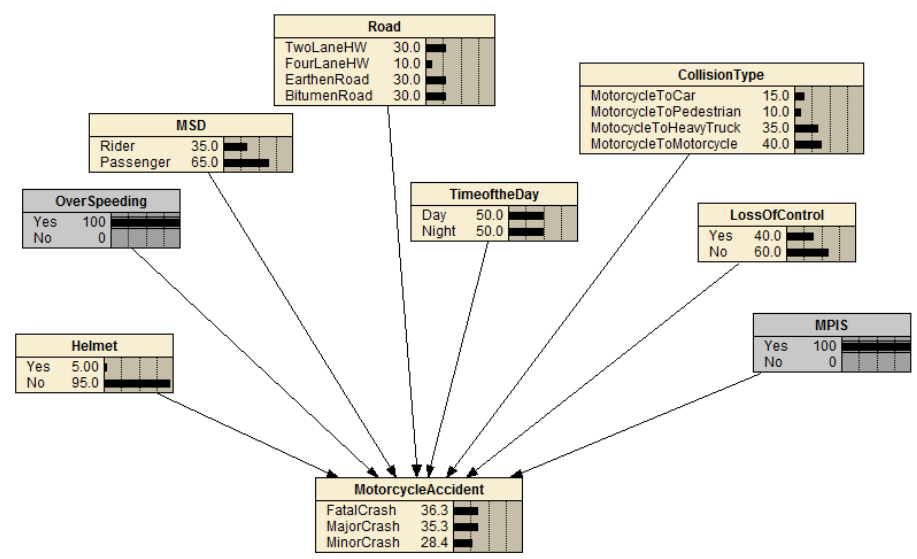

Fig. 17: Bayesian diagnostic inference showing the effect of the occurrence of OverSpeeding $=$ Yes $(100 \%)$ and MPIS $=$ Yes $(100 \%)$ when riding the motorcycle with MPIS.

\section{CONCLUSIONS}

The spread of coronavirus is an increasing global difficulty in recent times. Virtually all sectors of the society are experiencing the implications of the global pandemic. A notable strategy of preventing the spread of COVID-19 is through social distancing, but studies across a range of scientific fields on the global pandemic focused on causes, treatment and impacts. This study, however, presented the design and fabrication of a MPIS and assessment of its acceptability. This was to prevent the community spread of the virus. It is a study that centres on the concept of social distancing. The MPIS was fabricated from a mild steel frame with a transparent polymeric material used as the shield fixed on the frame using rivets joining system. The MPIS frame was upholstered to prevent it causing injury to the riders and passengers. Post riding evaluations revealed that $58 \%$ of the riders have challenges riding the motorcycle with MPIS, $41 \%$ of the riders complained about sitting posture, $31 \%$ about the riding stability, while about $14 \%$ about steering and riding. The probability of occurrence of fatal crash of motorcycle accident is $31.7 \%$, major crash of motorcycle accident is $34.5 \%$ and minor crash of motorcycle accident is $33.7 \%$ respectively Social evaluation of the motorcycle with MPIS showed a promising post riding result while uncertainty evaluation revealed the effects of higher speeds and the adapted MPIS in the event of the occurrence of motorcycle accident when riding the adapted MPIS motorcycle.

\section{ACKNOWLEDGEMENT}

The authors would like to thank the Tertiary Education Trust Fund (TETFUND) for the financial support under the institution-based research grant TETFUND/IBR/OOU/005. 


\section{REFERENCES}

[1] Liu, Q., Sun, J., Tian, Y., Ni, Y, Yu, S., Modelling and simulation of nonmotorized vehicles' dispersion at mixed flow intersections, Journal of Advanced Transportation, 2019, art. no. 9127062. https://doi.org/10.1155/2019/9127062.

[2] Oyesiku, O.O., Akinyemi, O.O., Giwa, S.O., Lawal, N.S., Adetifa, B.O., Development of bicycle and motorcycle carriage for goods mobility in rural areas of Nigeria, African Journal of Science and Nature, vol. 6 , 2018, p. 114-130.

[3] Oyesiku, O.O., Akinyemi, O.O., Giwa, S.O., Lawal, N.S., Adetifa, B.O., Evaluation of rural transportation technology: A case study of bicycle trailers and motorcycle trailers, Jurnal Kejuruteraan, vol. 31, no. 1, 2019 , p. 11-18.

[4] Munby, D., Transport, Journal of Transport Economics and Policy, Penguin, Harmondsworth, vol. 2, no. 1 1968, p. 129-131.

[5] Oyesiku, O.O., Akinyemi, O.O., Giwa, S.O., Lawal, N.S., Adetifa, B.O., Field performance optimization and engineering economic evaluation of bicycle trailers for goods mobility in rural areas of Nigeria, Case Studies on Transport Policy, vol. 8, no. 4, 2020, p. 1319-1328.

[6] Shen, Y., Li, C., Dong, H., Wang, Z., Martinez, L., Sun, Z., Handel, A., Chen, Z., Chen, E., Ebell, M.H., Wang, F., Yi, B., Wang, H., Wang, X., Wang, A., Chen, B., Qi, Y., Liang, L., Li, Y., Ling, F., Chen, J., Xu, G., Community outbreak investigation of SARS-CoV-2 transmission among bus riders in eastern China, JAMA Internal Medicine, vol. 180, no. 12, 2020, p. 1665-1671. https://doi.org/10.1001/jamainternmed.2020.5225

[6] Ehijiele, E., Coronavirus (Covid-19): The lockdown strategy in Nigeria, 2020. Available online on https://doi.org/10.20944/preprints202005.0201.v1 on June 29.

[7] Mogaji, E., Impact of COVID-19 on transportation in Lagos, Nigeria, Transportation Research Interdisciplinary Perspectives, vol. 6, 2020, 100154.

[8] Berrones-Sanz, L.D., The working conditions of motorcycle taxi drivers in Tláhuac, Mexico City, Journal of Transport \& Health, vol. 8, 2018, p. 73-80. https://doi.org/10.1016/j.jth.2017.04.008.

[9] Noland, R.B., Mobility and the effective reproduction rate of COVID-19, Journal of Transport \& Health, vol. 20, 2021, https://doi.org/10.1016/j.jth.2021.101016.

[10] Zheng, R., Xu, Y., Bi, Y., Wang, W., Ning, G., Spatial transmission of COVID-19 via public and private transportation in China, Travel Medicine and Infectious Disease, vol. 34, 2020, https://doi.org/10.1016/j.tmaid.2020.101626.

[11] Zhen, J., Chan, C., Schoonees, A., Apatu, E., Thabane, L., Young, T., Transmission of respiratory viruses when using public ground transport: A rapid review to inform public health recommendations during the COVID19 pandemic, South African Medical Journal, vol. 110, no. 6, 2020.

[12] Purnomo, J., Ardiansyah, T., Jakarta's motorcycle taxis get backpack shield for virus battle, Emerging Markets 2020, Reuters, Available at https://www.reuters.com/article/us-health-coronavirus-indonesia-motorcycidUSKBN23H1RJ, (accessed 28.05.2021).

[13] Athumani, H., Ugandan creates COVID shield for motorcycles, Voice of Africa News, 2020, available at https://www.voanews.com/africa/ugandan-creates-covid-shield-motorcycles, (accessed 28.05.2021).

[14] Rajhans, N.R., Amrutkar, A.S., Ergonomic posture for motorcycle riding, V.V.P College of Engineering, International Conference on Innovative Science and Engineering Technology, Rajkot, 2011.

[15] Stedmon, A., Robertson, S., Yates, T., Fitzpatrick, B., Profiling a new user group: Anthropometric data for motorcyclists, Contemporary Ergonomics, The Ergonomics Society, Taylor \& Francis, 2018. p. 779-784.

[16] Karuppiah, K., Salit, M.S., Ismail, M.Y., Ismail, N., Tamrin, S.B.M, Conceptual design of motorcycle's lumbar support using motorcyclists' anthropometric characteristics, Maejo International Journal of Science and Technology, vol. 5, no. 1, 2002, p. 69-82.

[17] Oluwadiya, S., Kolawole, I.K., Adegbehingbe, O.O., Olasinde, A.A, Agodirin, O., Uwaezuoke, S.C., Motorcycle crash characteristics in Nigeria: Implication for control, Accident analysis and prevention, vol. 41, no. 2, 2008, p. 294-298, https://doi.org/10.1016/j.aap.2008.12.002

[18] Ogunmodede, T.A., Adio, G., Ebijuwa, A.S., Oyetola, S.O., Akintola, J.O., Factors influencing high rate of commercial motorcycle accidents in Nigeria, American International Journal of Contemporary Research, vol. 2, no. 11,2012 , p. 130-140.

[19] Oyesiku, O.O., Odufuwa, B.O., Gender perspectives in travel behaviour of motorcycle passengers in Nigerian intermediate cities, Urban Mobility for All: Proceedings of the Tenth International CODATU Conference, Lom, Togo, 2002, p. 13-19.

[20] Oyesiku, O.O., From womb to tomb, 24th Inaugural Lecture, Olabisi Onabanjo University, Ago Iwoye, OOU Press, 2002. 